\title{
Impact of Active Learning on Performance and Motivation in Female Emirati Students
}

\author{
John Burt \\ Zayed University, Dubai \\ Discuss this paper online at http://groups.yahoo.com/LTHE/
}

\begin{abstract}
Students entering Zayed University are expected to become active participants in their learning. However, the majority of these students have come from a public education system that is recognized to focus on teacher-centered passive learning. Students may be unprepared for this transition. This paper reports on a case study of changes in performance and motivation for students transitioning from passive learning to active learning.

Three students from the public education system were followed through two consecutive courses employing increasing active learning. Methods included observations, surveys, and interviews. Results indicate that the initial transition from passive learning to active learning has a negative impact, mainly due to inadequate preparation. However, subsequent development of skills through exposure results in improvement to the extent that motivation and performance exceed high school levels. It is concluded that the transition from active learning has the capacity to greatly improve student achievement if properly managed.
\end{abstract}

\section{Introduction}

A global trend in education is the move from teacher-centered instruction to studentcentered instruction focused on active learning techniques (CUSE 1997). Studies cite, among other benefits, improved grades, retention, enjoyment, and critical thinking skills (Ebert-May et al., 1997; Magnussen et al., 2000; Lake, 2001).

Unfortunately, students from teacher-centered educational systems are unfamiliar with active learning and frequently have problems adapting to the new mode of learning (Marbach-Ad et al., 2001; Udovic et al., 2002). Due to their inexperience they often lack the skills needed to learn actively, and feel frustrated and unmotivated as a result. The purpose of this study is to determine whether or not active learning has a positive impact on motivation and performance in university students in the United Arab Emirates (UAE).

\section{Context}

The students discussed in this paper come from the UAE public education system which is widely known to focus on passive learning through teacher-centered lecturing (Shaw et al., 1995; Mawgood, 2000; Mpofu et al., 1998a, 1998b; Rugh, 2002). After graduation from high school students these students enrolled at Zayed University, a publicly funded institution providing higher education to female UAE citizens. The majority of students at Zayed University come from this same secondary system.

I have selected three students for this study based on their public education background, and the fact that they have spend two sequential semesters in classes where I could monitor their development. In their first year at the university these students had enrolled in both a Computer Applications and a Biological Concepts course, where I have had the opportunity to observe their learning as class instructor. 
These courses are mixed-ability with maximum class sizes of $15-20$ students, and are designed for general education (i.e. non-majors). Computer Applications is a highly standardized course regularly offered to approximately 15 class sections, while Biological Concepts has only two sections where I am the sole instructor. The students in this study were required to take Computer Applications along with all other students, but elected to enroll in biology over the options of chemistry and physics as part of their science requirement.

As every student at Zayed University is provided with a personal laptop for use in classes, the purpose of Computer Applications is to introduce students to a computer based learning environment and train them to use common software programs to an intermediate level. This course uses an almost entirely active learning approach centered on the individual learner. Typically in each module the students are initiated to the new software environment and relevant skills through a hands-on example that follows a instructor demonstration being displayed through digital projection. Each lesson is followed with a homework activity that reapplies skills. Following a series of introductory lessons, the students are given a contextbased project that develops on skills learned for that specific program, and reapplies skills from earlier modules. These projects use a standardized set of skills, but the topics are open ended and students complete their own individual project.

The students in this study enrolled in Biological Concepts the semester following completion of Computer Applications. Like the computer course, Biological Concepts focuses on active learning, though group work is emphasized much more than individual work.

Each week the biology students are assigned to rotating groups and into a rotating role as team leader, team recorder, team manager, or team member. These roles each have a detailed list of responsibilities that is laid out in the course syllabus and followed throughout the course. Each week the group analyzes the problem, develops research questions, investigates theoretical information related to the problem, conducts (and often designs) a laboratory study related to the problem, and collates their research into a formal report detailing their findings. This is formalized in lesson structure, but students also meet daily outside of class. Three weeks are divided throughout the semester for review, followed by summative assessment. It is only during these sections that lecturing takes place, though it is done in conjunction with class-wide discussions, group gaming (we use a Jeopardy theme), and diagramming (either individually or on whiteboard).

\section{Literature Review}

A review of literature on active learning and motivation indicates that active learning often increases student performance quantitatively, for example in grades, and qualitatively, such as with ability to think critically. However, in contexts where active learning approaches are new to students, there is a danger that students can become unmotivated due to inadequate preparation and unfamiliarity with the learning style. Provided that students are adequately prepared to work in an active learning context, though, this approach may have the capacity to foster strong intrinsic motivation for successful learning.

\section{Active learning}

Active learning has its roots in constructivist learning philosophy. Here learners generate, check, and restructure knowledge by comparing new ideas against their prior knowledge (CUSE 1997). Constructivist learning is not a passive process, but involves learners actively interacting with their environment and other people. Learners control their own learning by accepting or rejecting ideas based on what they already know, and sharing these constructed meanings with others (Wellington, 1994; Silberman, 1996). Such an active learning approach heavily reinforces construction of knowledge in learners.

Active learning is becoming quickly adapted to both the science and to information and communication technology (ICT) curricula. The scientific process itself, and the use of 
technology for the collection, analysis, and presentation of information, are both inherently active (CUSE, 1997; Haymore-Sandholtz et al., 1997; Boersma et al., 2001). Even so called 'traditional' science courses were typically accompanied by a practical laboratory experience, and the use of ICT in classrooms has had students working in hands-on contexts. Unfortunately, these experiences frequently have students follow a series of steps that they may not understand to reach answers that are often self-evident (HaymoreSandholtz, 1997; Darling, 2001). The central tenet of active learning is that for learning to occur students must be cognitively active not necessarily behaviorally active (Mayer, 1999).

Approaches to active learning may be centered on the individual, a small group, or the whole class. The key ingredient is that all students are actively engaged in developing their own learning. On an individual level, activities such as reading exercises, reflective journals, work internships, portfolios and concept maps have students acquiring, reflecting on, and reapplying their knowledge. Laboratory activities and pair-work have small groups working collaboratively to address problems. Class-wide discussions, role play, and participation in large-scale practical projects allow students to learn from and teach each other while being actively engaged on tasks (Harmin 1994).

Numerous studies support the benefits of active learning. A review of 96 educational studies by Semb and Ellis (1994) found that while students do learn from teacher-directed, passive approaches (such as straight lectures), learning is better retained if the material is taught through means that actively engage students with the content. This retention translates into higher grades compared with students exposed to teacher-centered approaches (Lake, 2001; McClanahan and McClanahan, 2002; O'Connell-McManus et al., 2003).

In addition to these traditional benchmarks of success, active engagement in science and ICT has been linked to enhanced development of higher-order skills such as problem solving ability (Koschmann et al., 1996; CUSE, 1997; Magnussen et al., 2000; Kilderry et al., 2003), critical thinking (Doig and Werner 2000), abstract reasoning (Kilderry et al., 2003; Rodrigues, 2003), interpersonal communication (Haymore-Sandholtz et al., 1997; Caprio et al., 1998; Schaffer, 2000; Marbach-Ad, et al., 2001), and independent learning (Koschmann et al., 1996; Haymore-Sandholtz et al., 1997; Hartland, 1998; Doig and Werner, 2000; Rodrigues, 2003).

Despite the positive impact on students' learning, the active learning approach is not without problems. Complaints are most often associated with students unfamiliar with active learning techniques (Marbach-Ad et al., 2001; Udovic et al., 2002). Students coming from rotelearning backgrounds in the sciences often dislike the approach (Caprio et al., 1998; Mpofu et al., 1998; Doig and Werner, 2000). They perceive that they are learning less than would be learned through traditional lectures (Lake, 2001; Marbach-Ad et al., 2001), even with what they feel is an excessively high workload (Udovic et al., 2002). Similarly, students new to active learning through computing technology are frequently frustrated because they are unfamiliar with skills required when collecting and filtering virtually limitless amounts of information in a non-sequential learning environment (Haymore-Sandholtz et al., 1997; Rodrigues, 2003). Thus, complete immersion in active learning may put students from passive learning backgrounds at risk.

\section{Active Learning \& Motivation}

One of the primary goals of education is to have student develop life-long learning skills. To reach this goal, their learning must take place in a context that drives them to achieve. Over the past few decades various theories have been proposed to explain behaviour resulting from achievement motivation (Sharpes, 1999). These theories have shifted from being based completely on reinforcement of observable behaviour to focusing on psychological variables such as beliefs, values and goals (Stipek, 2002).

Students exposed to active learning frequently cite the feeling of ownership of their learning and increased enjoyment as positive impacts of their experience (CUSE, 1997; McClanahan 
and McClanahan, 2002; O'Connell-McManus et al., 2003). These comments are supportive of theories of intrinsic motivation, where students are inherently driven to develop themselves as a result of the pleasure that is derived from achieving higher levels of understanding (Stipek, 2002). Additionally, self-system theory claims that the development of interpersonal relationships plays a significant role in motivating students to learn (Hanrahan, 2002). According to this theory, students who are placed in a dynamic, interactive environment will perform better than students who are socially segregated from one another (Stipek 2002). As active learning frequently has students collaborating either in small groups or as whole classes, this technique promotes motivation through development of interpersonal dialogue (Wellington, 1994; Haymore-Sandholtz et al., 1997). This results in students who are able and willing to learn more, have increased attention on tasks, and have better overall understanding of concepts (Hartland, 1998; DeLong et al., 2003; O'ConnellMcManus et al., 2003; Rodrigues, 2003).

While active learning increases motivation in most contexts, students unfamiliar with active learning often have decreased confidence and feel inadequately prepared (Mpofu et al., 1988b; Marbach-Ad et al., 2001). This could significantly impact a students' motivation to succeed (Ebert-May et al., 1997; Baldwin et al., 1999).

\section{Research Methods}

The purpose of this research is to use a critical case study to examine the research question that active learning improves student performance and motivation compared to passive learning techniques. A case study allows the investigation of complex interrelationships that embody a students' educational experience (Sturman 1997; Mertens 1998). This was a case analyzing three students who have had significant exposure to passive, teachercentered learning before immersion in an active, student-centered learning environment.

To enhance credibility of results, this case study was triangulated using observations, surveys, and an interview (Table 1). Triangulation is a means of validating results in qualitative studies where individual methods could be considered open to bias and lacking in realism, but are strengthened by interpretation alongside related data sources (Denzin, 1997). The research instruments are not included here for the sake of brevity, but are available on request. 
Table 1: General methods and related items used to assess impact of learning style on motivation.

\begin{tabular}{|l|l|}
\hline Method & Items Used \\
\hline Observations & $\begin{array}{l}\text { High-school composite grades } \\
\text { University composite grades } \\
\text { Computer Applications grades } \\
\text { Biological Concepts grades } \\
\text { Seminar/Learning Outcomes and Assessments (LOA) portfolio } \\
\text { Personal observations in Computer Applications and Biological } \\
\text { Concepts }\end{array}$ \\
\hline Surveys & $\begin{array}{l}\text { Perceptions of learning style survey } \\
\text { Non-majors biology self-efficacy instrument (from Baldwin et al. } \\
1999)\end{array}$ \\
\hline Interview & Active learning and motivation interview \\
\hline
\end{tabular}

The range of methods used in this study each employs multiple data sources, strengthening the validity of results for this case (Kohn 1997, Sturman 1997).

\section{Results and Analysis}

Analysis of results has been provided in the following three sections. Section 1 is a description of changes in learning contexts, Section 2 is an assessment of the impact of this change on performance, and Section 3 is an assessment of the impact of this change on motivation. These are followed by a conclusion on the overall impact of the transition from passive to active learning.

\section{Section 1: Comparisons of learning contexts}

Survey and interview results confirm that previous learning was primarily passive in nature. Learning was dominated by lectures, which were sometimes accompanied by demonstrations. There were little or no experiences with hands-on activity, classwide discussions, project based learning, or collaborative group work. By contrast, their university experience is very active in approach. Project-based learning and comprehension activities are used in nearly all courses, and most have components of collaborative work and open dialogue. Lecturing is still employed where relevant, but is used in conjunction with a variety of other approaches. The students felt that the amount of active learning in Computer Applications and Biological Concepts was similar to the amount experienced in their other university courses at the same time. Computer Applications used daily skills-based activities and focused on reapplication through project work. Biological Concepts had daily research activities, collaborative group-work, and discussions in addition to frequent hands-on labs and presentations.

\section{Section 2: Impact on Learning Performance}

The only official information available to indicate learning performance in high school is through summative course grades. These have been analyzed in conjunction with 
qualitative data from several sources. The following section examines changes in (a) grades, and (b) other measures of performance.

\section{2-a) Grades}

While many studies of active learning cite improvement in students' grades (see Lake, 2001; McClanahan and McClanahan, 2002; O'Connell-McManus et al., 2003), the grades of the students in this study have not changed since high-school. The average grade for the three students on completing high-school was $91.2 \%$, and their grade was exactly the same $(91.2 \%)$ in the past semester of university.

It is doubtful that high-school grades, however, reflect true understanding. Both published research (Shaw et al. 1995, Mawgood 2000, Rugh 2002) and the students' own comments point out that grading in the UAE public school system is based almost entirely on summative examination of factual information. Students commented that high-school grades measured ability to memorize information, rather than use skills. Additionally, a host of socio-psychological factors are also known to influence grade changes from high-school to university. These would include changes in teaching and learning style, level of content, and disruption of social bonds, among other factors (Dilsworth and Robinson, 1995; Laband and Hanby, 2003). This is particularly true in the case of these students, as language difficulty has most likely impacted their grades. ESL students are known to be at risk of poor performance moving to English-medium universities (Maloney 2003).

\section{2-b) Other measures of performance}

Aside from composite course grades, student performance has also been documented qualitatively. These other measure of performance have shown consistent improvement with exposure to active learning.

Students' performance on each software package in Computer Applications improved over time. They corrected any errors or deficiencies that were pointed out in feedback forms and improved with subsequent tasks. This pattern holds for each software package that was introduced. In Biological Concepts the pattern is more difficult to interpret, as most submissions are the result of group work. However, feedback provided on individual quizzes and presentations has resulted in an improvement of subsequent performance. Similarly, all students have improved their communication skills, use of information technology, and ability to work in teams as a result of her experiences. At $\mathrm{ZU}$ each student is required to build and maintain a portfolio of her academic work indicating competency in areas such as leadership and critical thinking (Zayed University, 2002). Improvement in these areas is evident in comments from University Seminar and Learning Outcomes Assessment instructors in the students' learning portfolios.

Student comments support these observations. They feel that active learning has not only promoted skills within subjects, but also their ability to transfer these skills to other contexts. One student commented that the different methods used in active learning "ensured that we could understand... if I didn't get something out of one method, I could learn it through another". Active learning has also had a significant impact on their ability to work with others. One student commented that in high school she disliked working in groups, but has now grown to enjoy the experience immensely. "I can talk about things and discuss them very freely and confidently.... I feel that I am getting better and more professional". These interpersonal experiences have helped all three students develop patience, cooperation, and flexibility. In all, the students' comments indicate that active learning has fostered a strong development of higher-order learning skills. 
To summarize, exposure to active learning appears to have improved general learning performance, though not grades. As grades are an unreliable measure of progress in this context, interpretation would not be valid. Performance in higherorder learning skills has improved in various contexts. Given that these results are triangulated through observations by three separate instructors in four courses (my courses and the LOA/Seminar courses), and by the students' own reflections, it can reliably be concluded that higher-order learning outcome skills have improved with exposure to active learning. Overall, active learning has had a positive impact on learning performance.

\section{Section 3: Impact on Motivation}

All three student responses in surveys and interviews indicated that they were most motivated by opportunities to develop learning and understanding, and by opportunities to distinguish themselves in the eyes of their peers and families. According to social cognitive theory, motivation is a result of thought processes, not of instincts or incentives (Miltiadou and Savenye, 2003). An individual's motivational construct can be classified into three general divisions: (a) their perception of their ability (self-efficacy, locus of control), (b) their reasons for engaging in tasks (goals), and (c) their strategies for accomplishing a task (self-regulation) (McCormack-Brown, 1999; Pajares, 2001; Miltiadou and Savenye, 2003). I have examined the students' motivation as a function of these three divisions.

\section{3-a) Motivation as a function of perception of ability}

An individual's perception of their ability to succeed heavily impacts their motivation (McCormack-Brown 1999), and is a powerful predictor of academic performance (Stipek, 2002). Self confidence in their ability and their perception of control of their learning play an important role in motivation.

\section{Impact of self-efficacy on perception of ability}

A person's judgment of their ability to succeed in academic pursuits is known as their academic self-efficacy belief (Pajares 2001). Each students' academic self-efficacy was measured using a standardized 23-item self-efficacy instrument for non-major biology students developed for the National Science Foundation. This instrument has been found to be a valid and reliable measure of confidence (Baldwin et al. 1999). (None was available for computing, though my observations and student comments indicate that their confidence is similar in that context). On a Likert scale from 1 (not at all confident) to 5 (totally confident), the average score for these three students was 4.04 , representing an overall perception of being very confident with biology. This is particularly meaningful when compared with results of the same survey from the biology cohort a year earlier. Those students were taught the exact same content mainly through lecture, without a focus on active learning. Their combined score was only 3.45 , indicating only fair confidence. The largest difference was noted for questions regarding confidence with methodology, a focus of active learning. Thus, active learning appears to have the capacity to increase a students' confidence, despite the fact that students find it challenging.

Aside from biology, the students felt that active learning has increased their confidence with skills in other subjects, ability to apply skills laterally to new contexts, and ability to work either alone or in groups. Passive learning did not instill this confidence. It is important to note that this increase in confidence represents a year of adjustment. All students commented that initially, active learning decreased their confidence due to their unfamiliarity with the approach. With exposure, confidence 
grew as students became comfortable with the learning style, until it exceeded highschool levels.

\section{Impact of locus of control on perception of ability}

Along with self-confidence, perception of self-control plays an important role in determining self-perception of ability. An individual's belief in how much their activity will influence a given outcome is termed their locus of control (McCormack-Brown, 1999; Miltiadou and Savenye, 2003). All three students exhibit traits of a highly internal locus of control, where they feels that their success or failure is a result of their own efforts. Class observation, surveys and the interview show that when faced with difficulties, these students take control of the situation and work to solve the problem, rather than leaving it unresolved. Internalization has been linked to increased motivation, academic achievement, and persistence in the face of challenges (Miltiadou and Savenye 2003).

Transition from passive learning to active learning does not appear to have influenced these students' locus of control. Comments on both high school and university experiences indicate that they felt control over their outcomes in both contexts. Though grades may be lower in university, the development of other skills (see above) may compensate. It appears that confidence plays a more influential role in perception of ability than does locus of control.

\section{3-b) Motivation as a function of reasons for engagement}

The reasons that individuals choose for engaging in academic activities also play a large role in social cognitive theory. These reasons for engagement are influenced by the goals that are set and by the rewards people place on these goals.

\section{Impact of goal orientation on reasons for engagement}

An achievement goal is what an individual is trying to accomplish. Two broad categories of goals are performance goals (also commonly known as ability goals) and learning goals (also known as mastery or task goals) (Pajares, 2001; Grant and Dweck, 2003). These students are an interesting case study in this regard, as their primary goals fall into both categories. While early research held that these were mutually exclusive, it is now accepted that they are interdependent of one another and both types of goal can be sought by an individual (Miltiadou and Savenye, 2003).

The students' focus on competence (in grades, opportunities for scholarship and generally doing well) is an outcome-based performance goal. Given that these students continue to perform well and maintain Dean's List standing, they are meeting their outcome goals and remaining motivated in that regard. Two of the students' additional goal of performing better than their classmates is a normative performance goal, in that they compare themselves with others. (The other student did not exhibit this goal). While the two students' grades are high, they are not substantially higher than average $(82.8 \%$ and $78.1 \%$ vs. $78.5 \%$ mean for Computer Applications and $90.1 \%$ and $85.2 \%$ vs. $79.2 \%$ mean for Biological Concepts). Yet both remain positive and motivated. It has been suggested that learners in this situation are buffered by their self-generated competitiveness, since it stimulates their interest in the subject and compensates for potential feelings of failure (Grant and Dweck, 2003). These students' frequent comments on heightened interest in challenging activities support this suggestion. To quote one: "I prefer classes with more active learning methods because they are more challenging." She later adds, "The workload/stress is higher but that makes you work harder!".

Both in the passive learning environment of high school and the active learning environment of university, these three students have met their performance goals. 
Grades in both contexts are high, and they continue to out-compete the majority of their peers for grades and status. As such, the transition from passive learning to active learning has had little impact on their motivation for academic engagement due to performance goals.

Along with performance goals, the three students consistently indicated a strong interest in learning goals. Learning goals are those that are oriented toward the acquisition of new skills or knowledge (Grant and Dweck, 2003). Through high-school and university, they have been motivated to fully understand the subject matter, to reapply skills and knowledge, and to challenge themselves mentally. Orientation toward learning goals has been linked to increased performance and persistence in the face of challenges (Pajares, 2001, Miltiadou and Savenye, 2003).

In Computer Applications and Biological Concepts the students felt the skills and content to be challenging, pushing them to work harder to fully understand the concepts. This is common of students with learning goal orientation, where studies have shown them to be resilient in the face of long-term difficulty (Pajares, 2001; Grant and Dweck, 2003). My impression from observations in classes and labs is that they gain a great deal of enjoyment out of succeeding at particularly difficult problems, and feel pride in being able to take responsibility for their own learning. This matches results that were seen in other situations where active learning was employed in place of traditional lecturing (CUSE, 1997; McClanahan and McClanahan, 2002; O'Connell-McManus et al., 2003).

While their learning goals themselves have not changed since high school, these students are now meeting those goals much more frequently. All feel that active engagement increases their enjoyment and encourages them to learn more. By contrast, they consistently felt that the passive learning environment of high school was 'boring' and did not help conceptual understanding. "Constant lecturing causes boredom and keeps the students away from actively interacting" commented one student. Another said, "...lecture based classes are boring, less effective.... There's no specific role for the student except to sit and listen". This distinction was particularly relevant for skills oriented tasks. All felt they learned little from observing teacher demonstrations in high school, and that hands-on use of skills in university helped to develop a deeper understanding. The third student commented that, "...I believe that I learn better when I try things [with] my own hands, rather than having it set up for me for memorization". In short, the transition from passive learning to active learning has had a profound positive impact in helping these students meet their learning goals.

\section{Impact of reinforcement on reasons for engagement}

In addition to goal orientation, incentives also play a strong role in determining an individuals reason for engagement on activities. Incentives fall into two categories: intrinsic and extrinsic motivation.

Extrinsic motivation is represented by rewards, such as grades or praise, from external sources (Miltiadou and Savenye, 2003). The goals of gaining high grades and respect from others indicate that these students are partially extrinsically motivated.

Intrinsic motivation is represented by the enjoyment we gain in challenging ourselves and exercising our capabilities (Miltiadou and Savenye, 2003). The goals of accomplishment, understanding, and personal challenge affect and are affected by intrinsic motivation. All feel a great deal of satisfaction and interest in learning for the sake of learning, and their comments indicate that this is their primary motivator. 
When asked about their primary motivators in high-school and learning the students first comments were all related to learning: "I wanted an understanding of the subject matter" said one, "for the sake of learning" said another. With regards to university "... it's advanced, and offers much higher challenges".

All three students continue to focus on performance goals that are met with extrinsic rewards. However, the transition from passive learning to active learning has offered them more opportunities to learn independently, to learn collaboratively, and to take active control of what and how much they learn. In this respect, each now has more opportunities to meet her learning goals and to subsequently be rewarded with intrinsic motivation. As a result, the relative proportion of the intrinsic reinforcement has increased with active learning, while extrinsic reinforcement has decreased. This will be of benefit, as intrinsic reinforcement is associated with persistence in the face of challenges, increased confidence, pleasure with learning, and better understanding, while extrinsic reinforcement has been associated with insecurity and low persistence (Pajares, 2001; Stipek, 2002).

\section{3-c) Motivation as a function of strategies for accomplishing tasks}

The techniques and strategies that an individual uses to accomplish tasks also factor into achievement motivation. Here the concern revolves around how individuals use cognitive strategies to reflect on, analyze, and accomplish tasks. This process is termed self-regulation (McCormack-Brown, 1999; Miltiadou and Savenye, 2003). Self-regulated learners use diverse cognitive strategies to approach problems, they use techniques such as planning and monitoring (metacognitive strategies) to control their progress towards their goals, and they manage resources needed to reach these goals. Self-regulation has been associated with increased performance and ability to conquer challenges (Stipek, 2002; Miltiadou and Savenye, 2003).

\section{Use of cognitive and metacognitive strategies to accomplish tasks}

Cognitive strategies are the thoughts and behaviors that an individual uses to accomplish a task. Metacognitive strategies are the approaches that result from an awareness and reflection on personal thoughts and capabilities (Stipek, 2002). Use of metacognitive strategies such as planning, monitoring and regulating are linked to deeper processing and retention of information (Miltiadou and Savenye, 2003).

Comments on high school classes indicate that metacognitive strategies were not actively developed. With reference to high-school biology, one student said, "Our role, as students, was to answer the questions in the lab book by watching and not actually contributing to the lab". In Computer Applications and Biological Concepts each has been required to plan and implement her own studies, to learn from her mistakes by correcting errors on assignments and tests, as well as reflect on and develop areas of deficiency based on semi-formal assessment discussions. This participation "makes students think... to participate and be fully engaged with the subject".

While these metacognitive skills are being actively pursued and developed through active learning, survey responses indicate that they are still in the developmental stage. Reflective exercises were among the least favored forms of active learning in two of the three students. They felt these exercises to be redundant and of little value to academic development. They would prefer external feedback. "... they make students repeat themselves... I prefer working perfectly on the project itself and get feedback on it..." said one, while the other said that "I don't like this type because it's not as interesting or as useful as other types of active learning". The transition from passive to active learning does appear to be gradually improving metacognition. While the two students above may need more opportunity to develop these 
strategies, the third sees great value in using reflection to identify and target weaknesses and deficiencies in her learning. She felt reflection "...helps students reflect on their own way of learning, discover their own strengths and weaknesses, and better understand the subject they're learning. It is also important because... when they analyze, criticize, and try to find a better solution by their own, they'll then find things are making more sense; as a student I can prove it!" As these strategies can be learned (Stipek 2002), with time it is expected that metacognitive skills will continue to grow in these students.

\section{Use of resource management to accomplish tasks}

In addition to using metacognitive strategies to accomplish tasks, self-regulated learners are able to plan and organize their tasks, manage their time and study environment, as well as learn from others (Stipek 2002, Miltiadou and Savenye 2003).

In Computer Applications, projects and assignments were initially designed to be fairly consistent for all students. As the course progressed, a more open ended approach was adopted, allowing individuals to develop and manage their independent work with limited direction. In Biological Concepts, this was extended. Each was simply given a problem and general directions at the beginning of the week and was required to investigate the theoretical and practical aspects of the problem both on her own and in a group. This involved coordinating schedules, lab supplies and equipment, as well as information resources related to the problem.

The passive learning environment in high-school fostered few resource management skills. All had little participation in group work, planning projects, or implementing practical investigations. Though the transition to active learning initially caused stress, all students found the challenge stimulating. Interview and survey results indicate that they now feels much more self reliant and productive than in high school. One student feels that "... with all the new skills that I gained... I got quite good experience that helps me work independently". Another said that she has "... grown in a way that made me realize how things can be interrelated, and this interrelation...has improved my skills in different areas". Clearly, the transition to active learning has promoted self-regulation through development of resource management skills.

The increasing development of these students' metacognitive skills in conjunction with their ability to manage their learning resources and environment will play a critical role in becoming self-regulated learners. This development of self-regulation should have a positive impact on the strategies available to accomplish tasks, and may increase the students' motivation to achieve.

In summary, social cognitive theory predicts achievement motivation as a result of three factors: personal perception of ability, reasons for engaging in tasks, and the strategies used to accomplish tasks ((McCormack-Brown, 1999; Pajares, 2001; Miltiadou and Savenye, 2003). The transition from passive learning to active learning has had a positive impact on all three of these factors. The students' increased selfefficacy has contributed to a higher perception of personal ability, the increased focus on learning goals contributed to intrinsically motivated academic engagement, and improved resource management skills, along with developing metacognitive skills, provides each student with strong strategies to accomplish tasks. None of the other social cognitive constructs examined have declined with exposure to active learning. These findings indicate that active learning has had a positive impact on factors affecting achievement motivation for each of the students. 


\section{Conclusion}

All students reported that performance and motivation both declined when first exposed to active learning, and remained low for approximately two months. They felt unconfident with the methods and skills required for independent learning, and were frustrated by their inability to perform at the same level as in high school. Similar observations were made in a study of a new active learning program initiated at United Arab Emirates University (Mpofu et al., 1998a, 1998b). Students in that study came from an educational background identical to the students in this study, and experienced similar problems on early exposure. This indicates a need to include an orientation to active learning in freshman courses at UAE colleges and universities. Over longer periods, however, motivation and performance increased to the extent that they surpassed high school levels.

The results of this study confirm that active learning improves student performance and motivation compared to passive learning techniques. While not improving grades, active learning has led to enhancement of overall performance with higherorder learning skills. Similarly, active learning has a positive impact on achievement motivation, particularly through development of self-confidence, metacognitive skills, and a focus on learning goals. These factors play together to make each of these students a self-directed, independent learner who seeks out new and challenging information for the betterment of herself and her knowledge.

\section{Reflection}

In the process of conducting and analyzing the results of this study, it became clear that active learning could and did contribute to a better learning experience for these students. Since its completion, I went on to modify this and other classes to better account for the results found here. While it was a successful experiment in most regards, one particular group of students encountered significant difficulty and stress with active learning, and I have had to subdue my interests. As cautioned above, the results here are for a group of only three students who may not be representative of the entire population. The later group that had problems was generally much weaker in English ability, and this may play a role in adaptability to active learning due to the reliance on verbal and written activities. This could be an area for further investigation.

\section{References}

Baldwin, J., D. Ebert-May, and D. Burns. (1999). The development of a college biology self-efficacy instrument for non-majors. Science Education, 83, pp. 397-408.

Boersma, S., M. Hluchy, G. Godshalk, J. Crane, D. DeGraff, and J. Blauth. (2001). Student-designed interdisciplinary science projects: Placing students in the role of the teacher. Journal of College Science Teaching, 30(6), pp. 397-402.

Caprio, M.W., P. Powers, J.D. Kent, S. Harriman, C. Snelling, P. Harris, and M. Guy. (1998). A path towards integrated science - the first steps: Constructivist teaching taking small steps to reach great strides. Journal of College Science Teaching, 27(6), pp. $430-434$.

Committee on Undergraduate Science Education (CUSE). (1997). Science Teaching Reconsidered: A Handbook. Washington, D.C.: National Academy Press.

Darling, R. (2001). Don't settle for imitation laboratory assignments: Introducing students to semester-long independent study projects. Journal of College Science Teaching. 31(2), pp. 102-105. 
DeLong, M., D. Winter and C.A. Yackel. (2003). Management, motivation and student-centered instruction I: Analytical framework. Primus : Problems, Resources, and Issues in Mathematics Undergraduate Studies, 13(2), pp. 97-123.

Denzin, N. (1997). Triangulation in educational research. In: J.P. Keeves (Ed). Educational Research, Methodology, and Measurement: An International Handbook, Second Edition. Oxford, UK: Elsevier Science Ltd. Pp. 318-322.

Dilsworth, M. and S. Robinson. (1995). K-12 and postsecondary education: Same issues, same consequences. The Educational Record, 76(2), pp. 82-90.

Doig, K. and E. Werner. (2000). The marriage of traditional lecture-based curriculum and problem-based learning: Are the offspring vigorous? Medical Teacher. 22(2), pp. 173-178.

Ebert-May, D, C. Brewer and S. Allred. (1997). Innovation in large lectures - teaching for active learning. Bioscience, 47(9), pp. 601-607.

Grant, H. and C. Dweck. (2003). Clarifying achievement goals and their impact. Journal of Personal and Social Psychology, 85(3), pp. 541-553.

Hanrahan, M. (2002). Learning science: Revisiting humanist dimensions of intellectual engagement. [Internet]. Queensland University of Technology, Faculty of Education. Accessed 27 September 2003 from <http://education.qut.edu.au/hanrahan/docs/ASERA/MH_ASERA02_PAPER1.DOC>. Harmin, M. (1994). Inspiring Active Learning: A Handbook for Teachers. Alexandria, VA: Association for Supervision and Curriculum Development.

Hartland, T. (1998). Moving towards problem-based learning. Teaching in Higher Education, 3(2), pp. 219-230.

Haymore-Sandholtz, J., C. Ringstaff, and D.C. Dwyer. (1997). Teaching with Technology: Creating Student Centered Classrooms. Columbia University, New York: Teachers College Press.

Kilderry, A., N. Yelland, V. Lazaridis, and S. Dragicevic. (2003). ICT and numeracy in the knowledge era: Creating contexts for new understandings. Childhood Education, 79(5), pp. 293-298.

Kohn, L. (1997). Methods in case study analysis. Technical Publication No. 2. Washington D.C, USA: The Center for Studying Health Systems Change.

Koschmann, T., A. Kelson, P. Feltovich, and H. Barrows. (1996). Computersupported problem-based learning: A principled approach to the use of computers in collaborative learning. In: T. Koschmann. CSCL: Theory and Practice of an Emerging Paradigm. New Jersey, USA: Lawrence Erlbaum Associates.

Laband D. and R. Hanby. (2003). Grading transfer versus continuing students in undergraduate forestry: Who will excel? Journal of Forestry, 101(7), pp. 35-39.

Lake, D. (2001). Student performance and perceptions of a lecture-based course compared with the same course utilizing group discussions. Physical Therapy, 81(3), pp. 896-902.

Magnussen, L., D. Ishida and J. Itano. (2000). The impact of using inquiry-based learning as a teaching methodology for the development of critical thinking. Journal of Nursing Education, 39(8), pp. 360-364.

Maloney, W. (2003). Creating success for at-risk first-year college students. Journal of Adolescent \& Adult Literacy, 46(8), p. 664-674. 
Marbach-Ad, G., O. Seal and P. Sokolove. (2001). Student attitudes and recommendations on active learning: A student led survey gauging course effectiveness. Journal of College Science Teaching, 30(7), pp. 434-438.

Mawgood, M. E. A. (2000). United Arab Emirates education 'Vision 2020': An overview. In: Welch, G. and E. A. El-Mawgood. Educational Reform in the United Arab Emirates: A Global Perspective. Surrey, UK: Ministry of Education and Youth UAE/ University of Surrey, pp. 5-37.

Mayer, R.H. (1999). Designing instruction for the cognitive classroom. In: C.M. Reigeluth. Instructional-Design Theories and Models, Volume II. London, U.K.: Lawrence Erlbaum Associates.

McClanahan, E.B. and L.L. McClanahan. (2002). Active learning in a non-majors biology class. College Teaching, 50(3): 92-96.

McCormack-Brown, K. (1999). Social cognitive theory overview. [Internet]. University of South Florida. Accessed 02 January, 2004 from

<http://hsc.usf.edu/ kmbrown/Social_Cognitive_Theory_Overview.htm>.

Mertens, D. (1998). Research Methods In Education And Psychology : Integrating Diversity With Quantitative \& Qualitative Approaches. Thousand Oaks, CA: Sage Publications.

Miltiadou, M. and W. Savenye. (2003). Applying social cognitive constructs of motivation to enhance student success in online distance education. Educational Technology Review, 11(1).

Mpofu, D.J.S., M. Das, T. Stewart, E. Dunn and H.J. Schmidt. (1998a). perceptions of group dynamics in problem-based learning sessions: A time to reflect on group issues. Medical Teacher, 20(5), pp. 421-427.

Mpofu, D.J.S., H.J. Schmidt, M. Das, J. Lanphear and E. Dunn. (1998b). A review of problem based learning: perceptions of students and tutors at the United Arab Emirates University. Education for Health, 11(2), pp. 203-213.

O'Connell-McManus, D., R. Dunn, and S.J. Denig. (2003). Effects of traditional lecture versus teacher-constructed \& student-constructed self-teaching instructional resources on short-term science achievements \& attitudes. The American Biology Teacher, 65(2), pp. 93-102.

Pajares, F. (2001). Toward a positive psychology of academic motivation. The Journal of Educational Research, 95(1), pp. 27-35.

Rodrigues, S. (2003). Conditioned pupil disposition, autonomy, and effective use of ICT in science classrooms. The Educational Forum, 67(3), pp. 266-275.

Rugh, W.A. (2002). Arab education: Tradition, growth and reform. The Middle East Journal, 56(3), pp. 396-414.

Schaffer, A. (2000). Improve classroom realism by allowing practitioners to present and evaluate your next class project. Journal of Engineering Technology, 17(2), pp. 52-56.

Semb, G.B. and J.A. Ellis. (1994). Knowledge taught in schools: What is remembered? Review of Educational Research, 64(2), pp. 253-286.

Sharpes, D. (1999). Advanced Psychology for Teachers. New York: McGraw-Hill.

Shaw, K., A. Badri, and A. Hukul. (1995). Management concerns in the United Arab Emirates state schools. The International Journal of Educational Management, 9(4), pp. 8-13. 
Silberman, M. (1996). Active Learning: 101 Strategies to Teach Any Subject. Massachusetts, USA: Allyn and Bacon.

Stipek, D. (2002). Motivation to Learn : Integrating Theory and Practice. Boston, USA: Allyn-Bacon.

Sturman, A. (1997). Case study methods. In: J.P. Keeves (Ed). Educational Research, Methodology, and Measurement: An International Handbook, Second Edition. Oxford, UK: Elsevier Science Ltd. Pp. 61-66.

Udovic, D., Morris, D., Dickman, A., Postlethwait, J and Wetherwax, P. (2002). Workshop biology: Demonstrating the effectiveness of active learning in a nonmajors biology course. BioScience, 52, pp. 272-281.

Wellington, J. (1994). Secondary Science: Contemporary Issues and Practical Approaches. London, UK: Routledge.

Zayed University. (2002). The Zayed University Academic Program Model. Dubai, UAE: Zayed University.

\section{About the Author}

John Burt has a MSc in Biology and a Post-Graduate Certificate in Education. He has been teaching at Zayed University for six years, and has implemented increasing levels of IT integration and active learning in his classes during that time. He has a number of publications and awards based on his work in the UAE. 